\title{
Synthesis and Solution Behavior of the Silicon-Containing Amphiphilic Block Copolymer, Polystyrene-b-Poly(3-hydroxymethylsilacyclobutane)
}

\author{
Kozo Matsumoto, Kana Miyagawa, Hideki Matsuoka, and Hitoshi Yamaoka ${ }^{\dagger}$ \\ Department of Polymer Chemistry, Kyoto University, \\ Kyoto 606-8501, Japan
}

(Received February 16, 1999)

\begin{abstract}
Aggregation behavior of a novel amphiphilic polycarbosilane block copolymer was investigated. Polystyrene- $b$-poly(3-hydroxymethylsilacyclobutane) (PSt- $b$-PHMSB) was synthesized by sequential anionic block polymerization of styrene with 1,1-dimethyl-3-methylenesilacyclobutane in benzene at room temperature, followed by hydroborationoxidation of $\mathrm{C}-\mathrm{C}$ double bonds. PSt- $b$-PHMSB was soluble in a nonpolar solvent such as toluene and polar solvent such as methanol. From the results of small-angle X-ray scattering (SAXS) measurement of the polymer solution, it was suggested that the amphiphilic polymer formed aggregates like micelles in toluene and methanol.

KEY WORDS 3-Methylenesilacyclobutane / Polystyrene / Poly(hydroxymethylsilacyclobutane) / Block Copolymer / Amphiphilic Polymer / Small-Angle X-Ray Scattering / Micellization /
\end{abstract}

Silacyclobutane is an important monomer for polycarbosilane synthesis ${ }^{1}$ and the polymerization of silacyclobutane derivatives has been widely investigated. ${ }^{2}$ One advantage of using silacyclobutanes as monomers in polycarbosilane synthesis is the feasible control of polymerization. Well-defined polycarbosilanes can be obtained by anionic ring-opening polymerization of silacyclobutanes. Recently, two independent research groups reported living anionic polymerization of 1,1-dialkyl substituted silacyclobutanes. ${ }^{2 a-c}$ Another significant advantage of the monomers is synthetic versatility. Various silacyclobutanes, which have substituents such as hydro, ${ }^{3}$ methyl, phenyl, vinyl, ${ }^{4}$ benzo, ${ }^{5}$ or ( $t$-butyldimethylsilyltrioxyethylene)phenyl ${ }^{6}$ groups were synthesized and polymerized. Previously, we have reported anionic polymerization of 3-methylenesilacyclobutanes. $^{7}$ Poly(3-methylenesilacyclobutane)s have reactive exomethylene groups and can be transformed into novel polymers by polymer reactions. Poly(3-methylenesilacyclobutane)s can be easily converted into poly(3hydroxymethylsilacyclobutane)s (PHMSB) by hydroboration $^{8}$ and successive oxidation of the carbon boron bonds (Scheme 1). This transformation is considered useful for polar polycarbosilane synthesis, since poly(3hydroxylmethyl-1,1-dimethylsilacyclobutane) prepared from poly(1,1-dimethyl-3-methylenesilacyclobutane) shows high polarity and is soluble in a polar solvent such as methanol.

Amphiphilic polymers, which have polar and nonpolar segments in one molecule, are attractive materials because

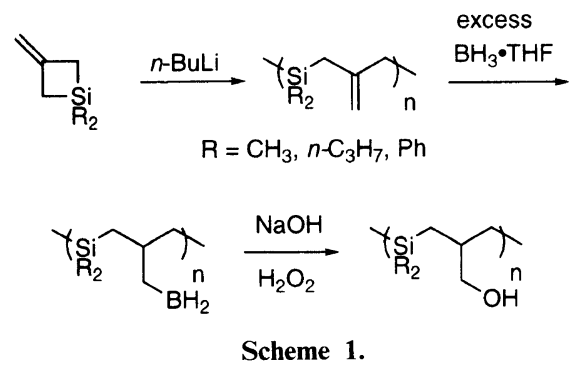

they exhibit self-assembling features such as surface adsorption or micelle formation in solution. ${ }^{9}$ Here, we synthesized an amphiphilic AB block copolymer: polystyrene- $b$-poly(1,1-dimethyl-3-hydroxymethylsilacyclobutane) using anionic polymerization of 3-methylenesilacyclobutane and examined its solution behavior.

\section{EXPERIMENTAL}

\section{Materials}

2-(Chloromethyl)-3-(trichlorosilyl)propene was prepared as reported. ${ }^{10}$ Styrene was washed three times with $1 \mathrm{M} \mathrm{NaOH}$, three times with water, dried over anhydrous $\mathrm{Na}_{2} \mathrm{SO}_{4}$, and distilled twice over calcium hydride under reduced pressure. Butyllithium hexane solution was purchased from Wako Pure Chemical Industry, $s$ butyllithium cyclohexane solution was purchased from Kanto Chemical Co., borane-tetrahydrofuran (THF) complex was from Aldrich, and used as delivered. Diethyl ether, THF, and benzene were freshly distilled over sodium benzophenone ketyl under an argon atmosphere before use.

\section{Measurements}

Gel permeation chromatography was carried out in chloroform on JASCO 880-PU chromatograph equipped with four polystyrene gel columns (shodex K-802, K-803, $\mathrm{K}-804$, and $\mathrm{K}-805$; exclusion limit $=5 \times 10^{3}, 7 \times 10^{4}$, $4 \times 10^{5}$, and $4 \times 10^{6}$, respectively) and JASCO 830 -RI refractive index detector. Molecular weights of polymers were calibrated with a polystyrene standard. ${ }^{1} \mathrm{H}$ and ${ }^{13} \mathrm{C}$ NMR spectra were recorded on a JEOL GSX 270 spectrometer in $\mathrm{CDCl}_{3}$, toluene- $d_{8}$, or methanol- $d_{4}$. IR spectra were measured on a JASCO IR-810 spectrometer. Small-angle X-ray scattering (SAXS) of polymer solution was measured using a Kratky-type camera manufactured by Rigaku Corporation, installed on a rotating anode $\mathrm{X}$-ray generator, and a position-sensitive proportional counter. Details of the SAXS instrument were previously reported. ${ }^{11}$

\footnotetext{
† To whom correspondence should be addressed.
} 
Synthesis of 1,1-Dimethyl-3-methylenesilacyclobutane

Magnesium $(2.11 \mathrm{~g}, 86.8 \mathrm{mmol})$ was activated by the addition of a small amount of iodine in THF $(66 \mathrm{~mL})$ under an argon atmosphere. A solution of 2-(chloromethyl)-3-(trichlorosilyl)propene $(14.4 \mathrm{~g}, 64.2 \mathrm{mmol})$ in THF $(33 \mathrm{~mL})$ was slowly added to the magnesium at $0^{\circ} \mathrm{C}$ with vigorous stirring over a period of $1 \mathrm{~h}$. The mixture was stirred for another $5 \mathrm{~h}$ after the addition. The mixture was cooled to $-48^{\circ} \mathrm{C}$ and methylmagnesium iodide (1.66 M diethyl ether solution, $73.6 \mathrm{~mL}, 122 \mathrm{mmol}$ ) was slowly added over a period of $0.5 \mathrm{~h}$. After being stirred for $2 \mathrm{~h}$, the reaction mixture was warmed to room temperature, poured into water $(100 \mathrm{~mL})$, and the products were extracted with pentane $(50 \mathrm{~mL})$. The organic layer was washed with water ten times. The volatile solvent was removed by heating the mixture to $50^{\circ} \mathrm{C}$. After most of the pentane and diethyl ether had been removed, the mixture was poured into water $(100 \mathrm{~mL})$ and extracted with pentane $(30 \mathrm{~mL})$ again. The organic layer was washed five times with water $(30 \mathrm{~mL})$ and pentane was removed by heating. Distillation under reduced pressure over calcium hydride gave 1,1-dimethyl3 -methylenesilacyclobutane $(2.0 \mathrm{~g}, 17.9 \mathrm{mmol})$ in $28 \%$ yield: bp $42^{\circ} \mathrm{C}$ (90 Torr); IR (neat) 3266, 2844, 2722, 1492, 1456, 1373, 1303, 1248, 1044, 999, $837 \mathrm{~cm}^{-1} ;{ }^{1} \mathrm{H}$ NMR $\left(\mathrm{CDCl}_{3}\right) \delta 0.30(\mathrm{~s}, 6 \mathrm{H}), 1,78(\mathrm{t}, J=1.8 \mathrm{~Hz}, 4 \mathrm{H})$, 4.69 (quint., $J=1.8 \mathrm{~Hz}, 2 \mathrm{H}) ;{ }^{13} \mathrm{C} \mathrm{NMR} .\left(\mathrm{CDCl}_{3}\right) \delta$ $-2.47,27.31,107.01,146.40$.

\section{Block Copolymerization of Styrene with 1,1-Dimethyl-3- methylenesilacyclobutane in $\mathrm{THF}$-Hexane}

Into a $100-\mathrm{mL}$ round-bottomed flask, equipped with a Teflon-covered magnetic stirring bar, rubber ballon and rubber septum, were placed THF $(6 \mathrm{~mL})$ and hexane $(6 \mathrm{~mL})$ under an argon atmosphere. Butyllithium $(0.80 \mathrm{M}$ hexane solution, $0.37 \mathrm{~mL}, 0.30 \mathrm{mmol}$ ) and styrene $(490 \mathrm{mg}, 4.7 \mathrm{mmol})$ were added at $-78^{\circ} \mathrm{C}$. The color of the solution turned orange and a polystyrene living polymer was obtained. After stirring for $30 \mathrm{~min}, 1,1-$ dimethyl-3-methylenesilacyclobutane was added. The color of the solution quickly turned yellow. The reaction mixture was stirred for another $1 \mathrm{~h}$ at $-78^{\circ} \mathrm{C}$. The reaction was terminated by adding water $(0.6 \mathrm{~mL})$ and the resulting mixture was poured into water $(30 \mathrm{~mL})$ and the products were extracted with toluene $(30 \mathrm{~mL})$. The organic layer was dried with anhydrous $\mathrm{Na}_{2} \mathrm{SO}_{4}$ and concentrated. Polystyrene- $b$-poly(1,1-dimethyl-3-methylenesilacyclobutane) was quantitatively obtained. ${ }^{1} \mathrm{H}$ NMR $\left(\mathrm{CDCl}_{3}\right) \delta 0.06(\mathrm{~s}), 1.25-2.35(\mathrm{~m}), 1.50(\mathrm{~s}), 4.40$ (s), $6.20-7.30(\mathrm{~m})$.

\section{Block Copolymerization of Styrene with 1,1-Dimethyl-3- methylenesilacyclobutane in Benzene}

Secondary butyllithium (1.16 M cyclohexane solution $0.26 \mathrm{~mL}, 0.30 \mathrm{mmol})$ was added to styrene $(520 \mathrm{mg}$, $5.0 \mathrm{mmol})$ in benzene $(12 \mathrm{~mL})$ under an argon atmosphere at $25^{\circ} \mathrm{C}$. The color of the solution turned orange and a polystyrene living polymer was obtained. After stirring for $1 \mathrm{~h}, 1,1$-dimethyl-3-methylenesilacyclobutane $(605$ $\mathrm{mg}, 5.4 \mathrm{mmol}$ ) was added. The color of the solution gradually turned pale yellow. The reaction mixture was stirred for another $1.5 \mathrm{~h}$ at $25^{\circ} \mathrm{C}$. The reaction was terminated by adding $\mathrm{MeOH}(0.5 \mathrm{~mL})$ and analogous 610
Table I. Results for block polymerization of styrene with 1,1-dimethyl-3-methylenesilacyclobutane

\begin{tabular}{|c|c|c|c|c|c|c|}
\hline \multirow{2}{*}{ Run } & \multirow{2}{*}{ Initiator } & \multirow{2}{*}{ Solvent } & Temp & \multirow{2}{*}{$\begin{array}{c}M_{n} \text { of } \\
\text { PSt }\end{array}$} & \multirow{2}{*}{$\begin{array}{c}M_{n} \text { of } \\
\text { products }\end{array}$} & \multirow{2}{*}{$\begin{array}{c}M_{w} / M_{n} \text { of } \\
\text { products }\end{array}$} \\
\hline & & & ${ }^{\circ} \mathrm{C}$ & & & \\
\hline 1 & $n-\mathrm{BuLi}$ & THF-hexane & -78 & 2400 & 4100 & 1.49 \\
\hline 2 & $s-\mathrm{BuLi}$ & Benzene & 25 & 2000 & 4000 & 1.21 \\
\hline
\end{tabular}

$M_{n}$ and $M_{w} / M_{n}$ estimated by GPC using polystyrene as the standard.

work up to the polymerization in THF-hexane gave polystyrene- $b$-poly(1,1-dimethyl-3-methylenesilacyclobutane) $(1.01 \mathrm{~g})$ with a small amount of polystyrene homopolymer.

\section{Synthesis of Polystyrene-b-Poly(1,1-dimethyl-3-hydroxy- methylsilacyclobutane) (PSt-b-PHMSB)}

A mixture of PSt- $b$-PMSB and PSt $(223 \mathrm{mg}$ ) prepared above was dissolved in THF $(10 \mathrm{~mL})$ and borane-THF complex (1.0 M THF solution, $2.0 \mathrm{~mL}, 2.0 \mathrm{mmol})$ was added under an argon atmosphere at $0^{\circ} \mathrm{C}$. After stirring for $2 \mathrm{~h}$, aqueous $\mathrm{NaOH}(3 \mathrm{M}, 2.0 \mathrm{~mL}, 6.0 \mathrm{mmol})$ was carefully added, and aqueous $\mathrm{H}_{2} \mathrm{O}_{2}(30 \mathrm{wt} \%, 710 \mathrm{mg}$, $42 \mathrm{mmol}$ ) was added. The resulting mixture was poured into water $(30 \mathrm{~mL})$ and extracted with diethyl ether $(30 \mathrm{~mL})$, dried with anhydrous $\mathrm{Na}_{2} \mathrm{SO}_{4}$ and concentrated in vacuo. The residue was washed with cyclohexane $(30 \mathrm{~mL})$ three times to remove PSt homopolymer, and dried in vacuo to afford polystyrene- $b$-poly(1,1-dimethyl3-hydroxymethylsilacyclobutane) (PSt- $b$-PHMSB) (156 $\mathrm{mg}$ ). IR (nujol) 3068, 1643, 1251, 1203, 1053, 998, 920, $843,801,766 \mathrm{~cm}^{-1} ;{ }^{1} \mathrm{H} \mathrm{NMR}\left(\mathrm{CD}_{3} \mathrm{OD}\right) \delta-0.08(\mathrm{~s})$, $0.30-0.82(\mathrm{~m}), 1.10-2.20(\mathrm{~m}), 1.65-1.85(\mathrm{~m}), 3.08-$ $3.32(\mathrm{~m}), 4.68-4.88(\mathrm{~m}), 5.50-7.80(\mathrm{~m}) ;{ }^{13} \mathrm{C}$ NMR $\left(\mathrm{CDCl}_{3}\right) \delta 145.32,128.00,127.62,125.61,69.31,43.50$, 40.31, 33.90, 21.93, - 0.93. Anal. Calcd for $\mathrm{C}_{4} \mathrm{H}_{9}\left(\mathrm{C}_{8^{-}}\right.$ $\left.\mathrm{H}_{8}\right)_{20}\left(\mathrm{C}_{5} \mathrm{H}_{14} \mathrm{OSi}\right)_{22} \mathrm{H}: \mathrm{C}, 71.01 \% ; \mathrm{H}, 9.62 \%$. Found: $\mathrm{C}$, $71.07 \%$; H, 9.79\%.

\section{RESULTS AND DISCUSSION}

Synthesis of Polystyrene-b-Poly(1,1-dimethyl-3-hydroxymethylsilacyclobutane) (PSt-b-PHMSB)

First, polystyrene- $b$-poly(1,1-dimethy-3-methylenelsilacyclobutane) (PSt- $b$-PMSB) was synthesized by the addition of 1,1-dimethyl-3-methylenesilacyclobutane to a living polystyrene. Two different reaction conditions were examined for the block polymerization and the results are summarized in Table I. Gel permeation chromatography charts of the obtained polymers are shown in Figures 1 and 2.

The addition of 1,1-dimethyl-3-methylenesilacyclobutane to a living polystyrene in $\mathrm{THF}$-hexane at $-78^{\circ} \mathrm{C}$ gave PSt- $b$-PMSB (Scheme 2). The formation of a block polymer was confirmed by GPC measurement. GPC shifted to a higher molecular weight region after the addition of the second monomer (Figure 1). However, molecular weight distribution of the product was not narrow $\left(M_{w} / M_{n}=1.49\right)$, probably because chain transfer or chain termination of 1,1-dimethyl-3-methylenesilacyclobutane polymerization may have occurred under this condition. But PSt- $b$-PMSB was obtained by the addition 


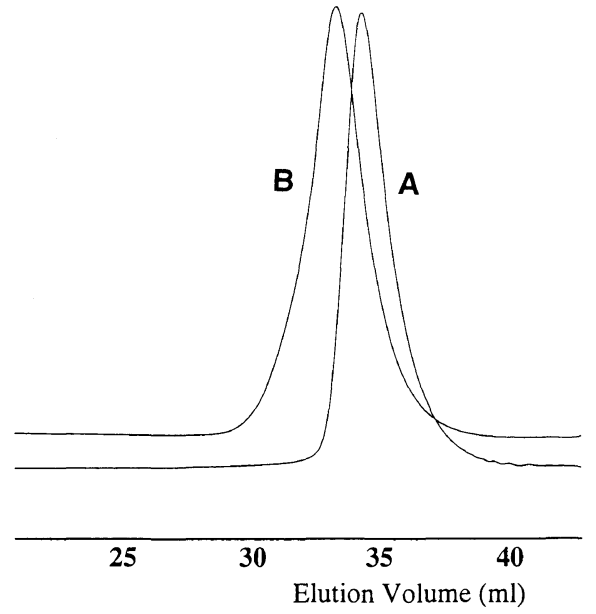

Figure 1. GPC charts for A: Polystyrene prepolymer synthesized in THF -hexane at $-78^{\circ} \mathrm{C}$. B: Polymers obtained after addition of 1,1-dimethyl-3-methylenesilacyclobutane in THF-hexane at $-78^{\circ} \mathrm{C}$.

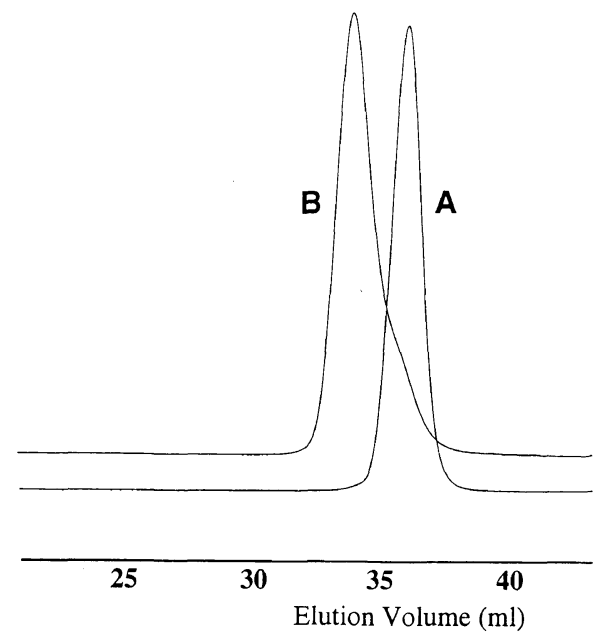

Figure 2. GPC charts for A: Polystyrene prepolymer synthesized in benzene at $25^{\circ} \mathrm{C}$. B: Polymers obtained after addition of 1,1-dimethyl3-methylenesilacyclobutane in benzene at $25^{\circ} \mathrm{C}$.

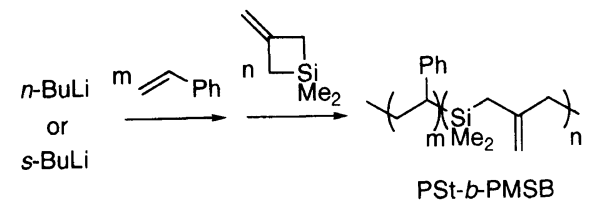

Scheme 2 .

of 3-methylenesilacyclobutane to a living polystyrene, ${ }^{12}$ while poly(1,1-dimethylsilacyclobutane)- $b$-polystyrene was not obtained efficiently by this technique. ${ }^{2 \mathrm{c}}$ From the results, it is assumed that the reactivity of the monomers is in the order of 1,1-dimethylsilacyclobutane $\geq$ styrene $>$ 1,1-dimethyl-3-methylenesilacyclobutane, and that the reactivity of the propagation end is in the order of poly(1,1-dimethylsilacyclobutane) $>$ polystyrene. Block polymerization in benzene at $25^{\circ} \mathrm{C}$ proceeded more cleanly to give PSt- $b$-PMSB which has narrower molecular weight distribution. Molecular weight distribution $\left(M_{w} / M_{n}\right)$ of the obtained polymer was 1.21 . Although the product was still contaminated by a small amount of styrene homopolymer, the GPC curve shifted to a higher molecular weight region, keeping the narrow peak sharp even after addition of the second monomer (Figure 2).

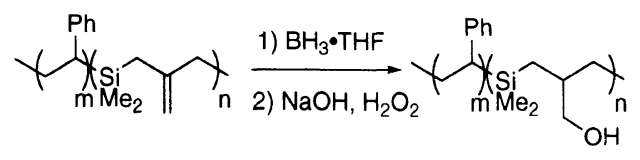

PSt-b-PHMSB

Scheme 3.

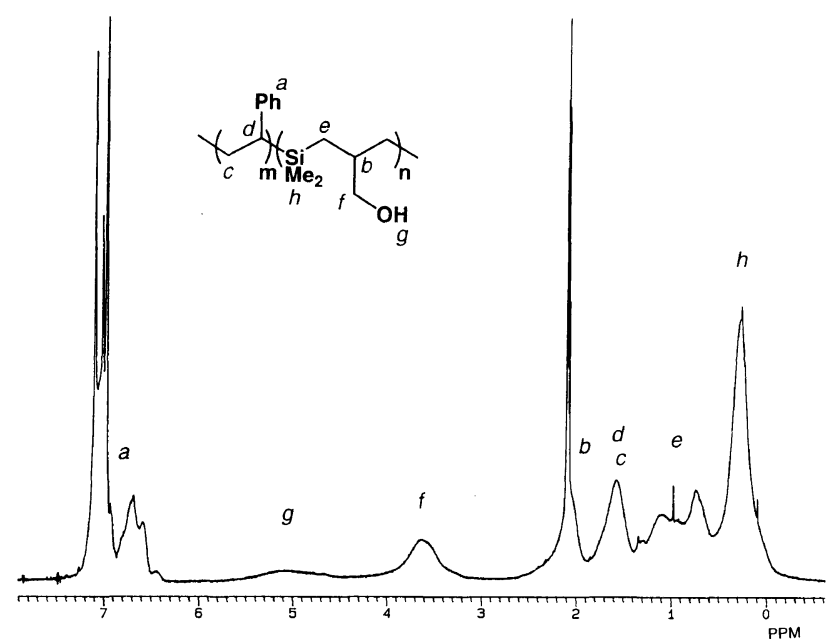

Figure 3. $270 \mathrm{MHz} \quad{ }^{1} \mathrm{H} \quad \mathrm{NMR}$ spectrum for PSt- $b$-PHMSB in toluene- $d_{8}$.

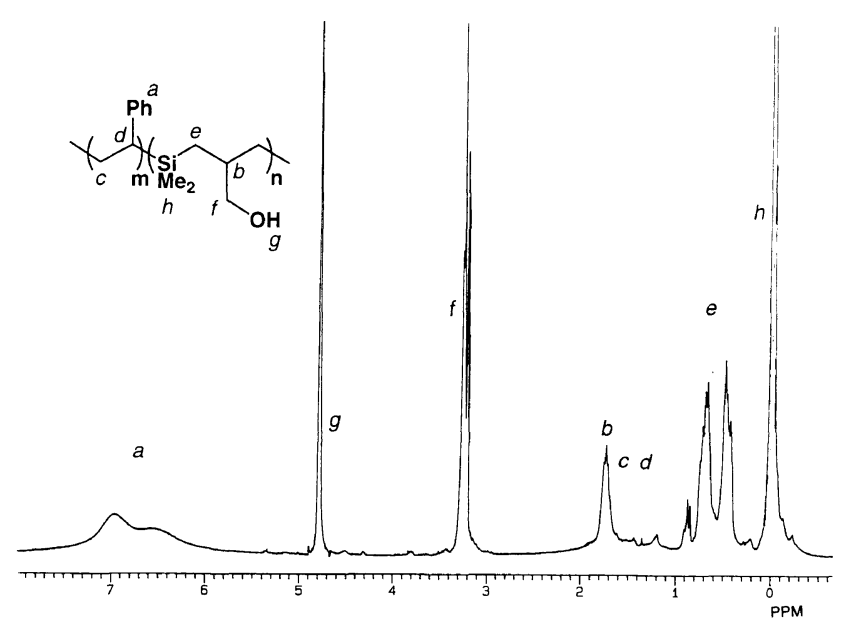

Figure 4. $270 \mathrm{MHz}{ }^{1} \mathrm{H}$ NMR spectrum for PSt- $b$-PHMSB in methanol- $d_{4}$.

From GPC measurements, $M_{n}$ of the products was tentatively estimated as 4100 in run 1 and as 4000 in run 2 using polystyrene as the standard. $M_{n}$ of the polystyrene segments in the obtained polymers could be estimated as 2400 in run 1 and as 2000 in run 2 by GPC analysis of the styrene prepolymers.

PSt- $b$-PHMSB was obtained by treatment of PSt- $b$ PMSB with excess borane-THF complex in THF and followed by oxidation with basic hydrogen peroxide (Scheme 3). The ratio of polymerization degree for PSt segment to PHMSB was determinded as $20: 22$ from the result of elemental analysis. Solubility of PSt- $b$-PHMSB was examined. PSt- $b$-PHMSB was soluble in a nonpolar solvent such as toluene or chloroform and a polar solvent such as methanol.

Proton NMR spectra of PSt- $b$-PHMSB in nonpolar (toluene- $d_{8}$ ) and polar (methanol- $d_{4}$ ) solvents are shown in Figures 3 and 4. 


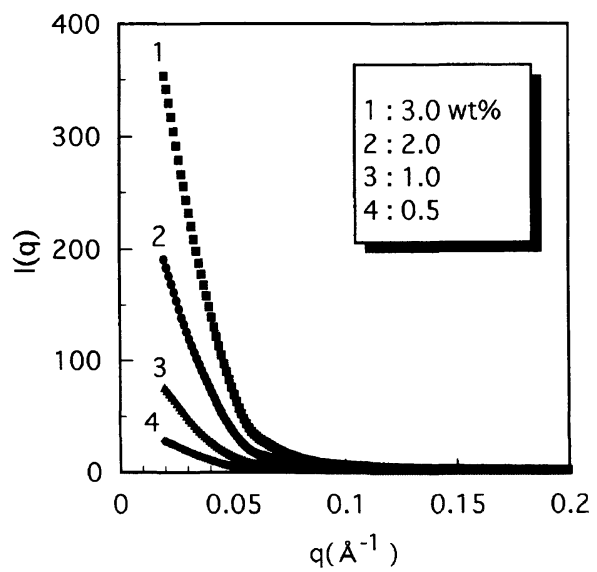

Figure 5. SAXS profiles for PSt- $b$-PHMSB in toluene. $q$ is a scattering vector, $I(q)$ is relative scattering intensity.

Although the PHMSB homopolymer is insoluble in toluene, signals assigned to the PHMSB segment were detected in toluene- $d_{8}$ (Figure 3 ). Similarly, signals assigned to PSt were detected in methanol- $d_{4}$, while PSt homopolymer was insoluble in methanol (Figure 4). Interestingly however, these signals were broad. Signal $h$ (PHMSB) in toluene- $d_{8}$ was broader than that in methanol- $d_{4}$. In the same fashion, signal $a$ (PSt) in methanol- $d_{4}$ was broader than that in toluene- $d_{8}$. These phenomena were caused by weak interactions between the PHMSB segment and toluene, and between the PSt segment and methanol, suggesting micelle formation of the block polymer in each solvent.

\section{Small-Angle X-Ray Scattering (SAXS) Analysis of PSt-b-PHMSB}

To investigate the solution behavior of PSt- $b$-PHMSB in more detail, small-angle X-ray scattering (SAXS) measurements of the polymer solution were performed in toluene, methanol, and toluene-methanol $(1: 1)$ mixed solvent.

Figure 5 shows the results of SAXS measurement in toluene. A strong scattering in the small-angle region was observed. This indicates the existence of aggregates. Although the intensity of the X-ray scattering decreased as the polymer concentration decreased, the shapes of the profiles did not depend on polymer concentration. The size and shape of the aggregates were thus fixed as the polymer concentration changed and critical micelle concentration (CMC) is far less than $0.5 \mathrm{wt} \% .^{13}$ To evaluate size of aggregates, fitting of the experimental profile by theoretical curve was performed. For calculation, a spherical core-shell model was assumed as the micelle structure, where the central core consisted of a polar PHMSB segment and the outer shell of a nonpolar PSt segment swollen by toluene. Theoretical curves for the model were calculated as follows:

$$
\begin{array}{r}
I(q)=n^{\prime}\left[4 \pi / 3 \cdot R_{\mathrm{c}}^{3}\left(\rho_{\mathrm{c}}-\rho_{\mathrm{s}}\right) \Phi\left(R_{\mathrm{c}} q\right)\right. \\
\left.+4 \pi / 3 \cdot R_{\mathrm{s}}^{3}\left(\rho_{\mathrm{s}}-\rho_{0}\right) \Phi\left(R_{\mathrm{s}} q\right)\right]^{2} \\
\Phi(x)=3\left[(\sin x-x \cos x) / x^{3}\right],
\end{array}
$$

where $n^{\prime}$ is the number density of the micelle; $R_{\mathrm{c}}$ and $R_{\mathrm{s}}$ are the radii of the core and of the whole micelle, respectively; and $\rho_{\mathrm{c}}, \rho_{\mathrm{s}}$, and $\rho_{0}$ are the electron densities

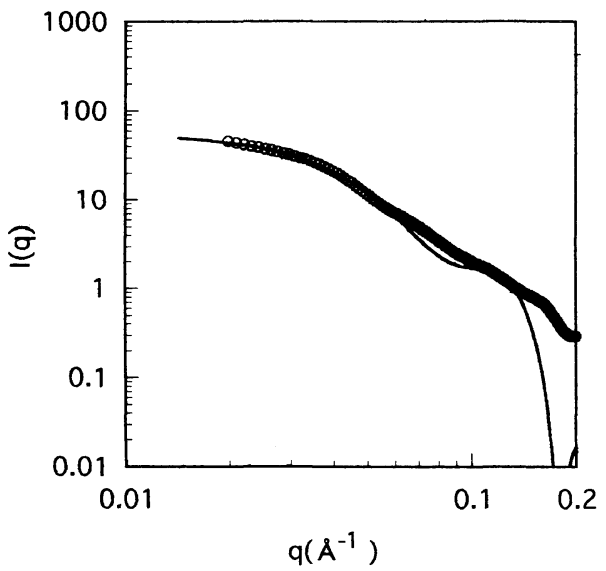

Figure 6. SAXS profile for PSt- $b$-PHMSB $1.0 \mathrm{wt} \%$ toluene solution. The solid curve is drawn according to core-shell model calculation.

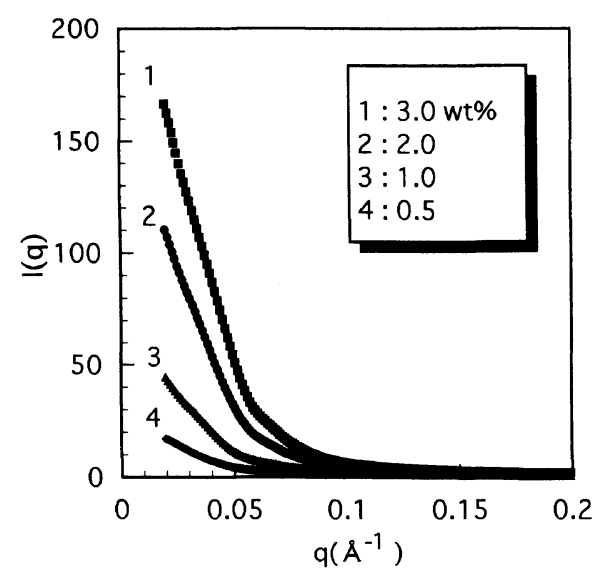

Figure 7. SAXS profiles for PSt- $b$-PHMSB in methanol.

of the core, shell, and solvent, respectively; $q$ (scattering vector) is $4 \pi \sin \theta / \lambda$ with wavelength $\lambda$ and scattering angle $2 \theta$.

The radius of the core $\left(R_{\mathrm{c}}\right)$ was estimated as $24 \AA$, and that of the whole micelle $\left(R_{\mathrm{s}}\right)$, as $69 \AA$ (Figure 6). The aggregation number of the micelle $\left(N_{\text {agg }}\right)$ in toluene was calculated as,

$$
N_{\text {agg }}=V_{\mathrm{c}} /\left(n \cdot v_{\text {PHMSB }}\right)
$$

where $V_{\mathrm{c}}$ is volume of the core, $n$ degree of polymerization of PHMSB, and $v_{\mathrm{PHMSB}}$, volume of PHMSB repeat units.

Figure 7 shows SAXS profiles of the block polymer in methanol. A strong scattering in the small-angle region was observed, indicating that the existence of aggregates and $\mathrm{CMC}$ is less than $0.5 \mathrm{wt} \%$ similarly to the case of the toluene solution. Theoretical curves for the spherical core-shell micelle were obtained. For calculation of methanol solution, it was assumed that the core was formed with a nonpolar PSt segment and the shell was formed with PHMSB and methanol. $R_{\mathrm{c}}$ and $R_{\mathrm{s}}$ of the micelle were estimated as $37 \AA$ and $89 \AA$, respectively (Figure 8). The aggregation number of the micelle $\left(N_{\mathrm{agg}}\right)$ was obtained as

$$
N_{\mathrm{agg}}=V_{\mathrm{c}} /\left(m \cdot v_{\mathrm{PSt}}\right)
$$

where $V_{\mathrm{c}}$ is volume of the core, $m$ degree of polymerization of PSt, and $v_{\mathrm{PSt}}$ volume of PSt repeat units.

The fitting results of toluene and methanol solutions 


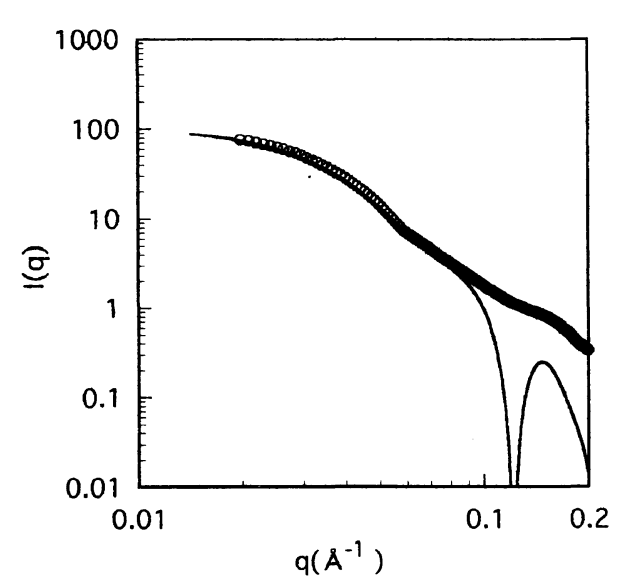

Figure 8. SAXS profile for PSt- $b$-PHMSB $1.0 \mathrm{wt} \%$ methanol solution. The solid curve is drawn according to core-shell model calculation.

Table II. Fitting results of SAXS profiles

\begin{tabular}{lcccc}
\hline \multirow{2}{*}{ Solvent } & $R_{\mathrm{c}}$ & & $\mathrm{R}_{\mathrm{s}}$ & $N_{\text {agg }}$ \\
\cline { 2 - 3 } & $\AA$ & & $\AA$ & \\
\hline Methanol & 37 & & 89 & 64 \\
Toluene & 24 & & 69 & 11 \\
\hline
\end{tabular}

are summarized in Table II. The aggregation number of micelle in methanol is much larger than that in toluene, possibly because the repulsive interaction between PSt segment and methanol is greater than that between PHMSB segment and toluene.

No strong scattering was observed for the polymer solution in toluene and methanol $(1: 1)$ mixed solvent, in which the block polymer did not form aggregates.

\section{CONCLUSION}

Polymerization of 3-methylenesilacyclobutane was applied to synthesis of amphiphilic block polycarbosilane. A novel polymer, PSt- $b$-PHMSB, was synthesized by block polymerization of styrene with 3-methylenesilacyclobutane, followed by hydroboration-oxidation. The polymer was soluble in nonpolar and polar solvents. From ${ }^{1} \mathrm{H}$ NMR and SAXS, it was deduced that the core-shell micelles of the polymer were formed in polar and nonpolar solvents.

Acknowledgments. The present work was supported by Grant-in-Aid for Scientific Research in Priority Area "New Polymers and Their Nano Organized Systems" (No. 10126229) from Ministry of Education, Science,
Sports and Culture of Japan.

\section{REFERENCES AND NOTES}

1. (a) M. Zeldin, K. J. Wynne, and H. R. Allcock, "Inorganic and Organometallic Polymers," ACS Symposium Series 360, American Chemical Society, Washington, D.C., 1988. (b) J. M. Zeigher and F. W. G. Fearon, "Silicon-Based Polymer Science," Advances in Chemistry Series 224, American Chemical Society, Washington, D.C., 1990. (c) J. G. Richard, "Silicon-Containing Polymers," The Royal Society of Chemistry, Cambridge, 1995. (d) H. R. Kricheldorf, "Silicon in Polymer Synthesis," Springer-Verlag, Berlin, 1996

2. (a) K. Matsumoto, M, Deguchi, M. Nakano, and H. Yamaoka, J. Polym. Sci., Part A, Polym. Chem., 36, 2699 (1998). (b) R. Knischka, H. Frey, U. Rapp, and F. J. Mayer-Posner, Macromol. Rapid. Commun., 19, 455 (1998). (c) K. Matsumoto, H. Shimazu, M. Deguchi, and H. Yamaoka, J. Polym. Sci., Part A, Polym. Chem., 35, 3207 (1997) and (d) references cited therein. (e) K. Komuro and Y. Kawakami, Polym. J., 31, 138 (1999).

3. C. X. Liao and W. P. Weber, Polym. Bull., 28, 281 (1992).

4. C. X. Liao and W. P. Weber, Macromolecules, 25, 1639 (1992).

5. M. Theuring, S. J. Sargeant, G. Manuel, and W. P. Weber, Macromolecules, 25, 3834 (1992).

6. K. Matsumoto, H. Shimazu, and H. Yamaoka, J. Polym. Sci., Part A, Polym. Chem., 36, 225 (1998).

7. K. Matsumoto, K. Miyagawa, and H. Yamaoka, Macromolecules, 30, 2524 (1997)

8. (a) H. C. Brown, P. K. Jadhav, and A. K. Mandal, Tetrahedron, 37, 3547 (1981). (b) H. Kano and J. Hooz, Org. Synth., 53, 77 (1973).

9. (a) I. Piirma, "Polymeric Surfactants," Surfactant Science Series Vol. 42, Marcel Dekker, Inc., New York, N.Y., 1992. (b) M. Moffitt, K. Khougaz, and A. Eisenberg, Acc. Chem. Res., 29, 95 (1996). (c) B. Chu, Langmuir, 11, 414 (1995). (d) W. Brown, K. Schilln, and S. Hvidt, J. Phys. Chem., 96, 6038 (1992). (e) K. Mortensen and W. Brown, Macromolecules, 26, 4128 (1993). (f) R. Nagarajan and K. Ganesh, J. Chem. Phys., 98, 7440 (1993). (g) L. Zhang, R. J. Barlow, and A. Eisenberg, Macromolecules, 28, 6055 (1995). (h) J. Zhu, R. B. Lennox, and A. Eisenberg, $J$. Phys. Chem., 96, 4727 (1992). (i) C. Amiel, M. Sikka, J. W. Schneider, Y.-H., Tsao, M. Tirrell, and J. W. Mays, Macromolecules, 28, 3125 (1995). (j) D. Nguyen, C. E. Williams, and A. Eisenberg, Macromolecules, 27, 5090 (1994). (k) H. Yamaoka, H. Matsuoka, K. Sumaru, S. Hanada, M. Imai, and D. G. Wignall, Physica B, $213 \&$ 214, 700 (1995). (1) M. Nakano, M. Deguchi, K. Matsumoto, H. Matsuoka, and H. Yamaoka, Macromolecules, submitted. (j) M. Nakano, M. Deguchi, H. Endo, K. Matsumoto, H. Matsuoka, and H. Yamaoka, Macromolecules, submitted.

10. B. M. Trost, M. Buch, and M. L. Miller, J. Org. Chem., 53, 4887 (1988).

11. N. Ise, T. Okubo, S. Kunugi, H. Matsuoka, K. Yamamoto, and Y. Ishii, J. Chem. Phys., 81, 3294 (1984).

12. A sequential addition experiment of styrene to poly(3methylenesilacyclobutane) prepared in $\mathrm{THF}$-hexane at $-78^{\circ} \mathrm{C}$ was not attempted because the anionic polymerization of 3-methylenesilacyclobutane under the condition does not show a living nature.

13. The scattering intensity of X-ray from more dilute solution than $0.5 \mathrm{wt} \%$ was so weak that it was not able to discuss about CMC in detail from SAXS data. 